\title{
COMPORTAMENTO HUMANO NAS ORGANIZAÇÕES: DESAFIOS FRENTE ÀS MUDANÇAS ENTRE OS PROFISSIONAIS DE UM CALL CENTER
}

\author{
https://dx.doi.org/10.48097/2674-8673.2022n6p04
}

\author{
Arandi Maciel Campelo ${ }^{1}$ \\ Isis Luiza Gomes da Silva ${ }^{2}$ \\ José Felipe da Silva Pereira ${ }^{3}$ \\ Josiane Maria Gomes Calado ${ }^{4}$ \\ Wilson Reis de Alcântara ${ }^{5}$
}

\section{RESUMO}

Este artigo procurou investigar o comportamento humano em uma empresa com intervalo variável de 4 turnos. Alguns trabalhadores foram expostos a condições que traziam o desânimo na equipe, fazendo com que as pessoas deixassem de produzir, muitas vezes por falta de comunicação, pois há gestores que não sabem se impor com tal cargo. A pesquisa bibliográfica teve como principal balizador Chiavenato $(2005 ; 2019)$. O propósito deste artigo é esclarecer para as pessoas a estarem sempre motivadas em seu trabalho, contribuindo para que todos os participantes possam trabalhar e ser feliz, podendo identificar as vantagens que a motivação oferece para as empresas de Call Center, analisando as inúmeras formas de utilização para a melhoria do ambiente de trabalho. A pesquisa de campo, realizada na empresa Neobpo, em 2021, foi de natureza qualitativa e propositiva, tendo como principal instrumento de coleta de dados o questionário. Os dados de campo demonstraram que mesmo muitas vezes as pessoas tem medo de demostrar o que pensa.

Palavras-chave: Comportamento humano nas organizações. Mudanças organizacionais. Conflitos organizacionais.

\footnotetext{
1 Orientador: Doutor em Educação - Universidade Federal de Pernambuco; Administrador - Universidade de Pernambuco - FCAP/UPE; Mestre em Planificación y Gestion Organizacional - UniversidadAutonoma de Madrid / Espanha; Mestre em Dirección y Organización de Hospitales y Servicios de Salud - Universidad Politécnica de Valencia / Espanha; Especialista em Marketing - FCAP/UPE; Consultor em Sistemas Organizacionais, desde 1984; Professor e Diretor Acadêmico da Faculdade Metropolitana da Grande Recife. Email: arandi.campelo@globo.com
}

2 Concluinte do curso de Gestão em Recursos Humanos da Faculdade Metropolitana da Grande Recife.

E-mail: josefelipead@outlook.com.br

${ }^{3}$ Concluinte do curso de Gestão em Recursos Humanos da Faculdade Metropolitana da Grande Recife.

E-mail: josianecalado1987@gmail.com

${ }^{4}$ Concluinte do curso de Gestão em Recursos Humanos da Faculdade Metropolitana da Grande Recife.

E-mail: isis.luiza@hotmail.com

${ }^{5}$ Concluinte do curso de Gestão em Recursos Humanos da Faculdade Metropolitana da Grande Recife.

E-mail: wr.alcantara.ss@gmail.com 


\begin{abstract}
This article sought to investigate human behavior in a company with a variable interval of 4 shifts. Some workers were exposed to conditions that bring discouragement to the team, causing people to stop producing, often due to lack of communication, as there are managers who do not know how to impose themselves with such a position. The bibliographical research had Chiavenato $(2005 ; 2019)$ as its main guide. The purpose of this article is to clarify for people to be always motivated in their work, contributing so that all participants can work and be happy, identifying the advantages that motivation offers to Call Center companies, analyzing the numerous ways of use for the improvement of the working environment. The field research, carried out at the Neobpo company, in 2021, was qualitative and purposeful, having the questionnaire as the main instrument for data collection. Field data showed that even many times people are afraid to show what they think.
\end{abstract}

Keywords: Human behavior in organizations. Organizational changes. Organizational conflicts.

\title{
INTRODUÇÃO
}

O presente cenário apresenta inúmeras mudanças que têm impactos diretos e imediatos na forma de agir de cada indivíduo. Logo, o setor de Call Center representa bem o extremo não valorizado, uma vez que ele utiliza muito mais atividades em menor período de tempo, apesar da moderna tecnologia utilizada no trabalho dos operadores. Embora muitas vezes não percebida pelas organizações, essa inconsistência entre as ênfases atribuídas à tecnologia e às pessoas pode minar as pretensões de se construir um relacionamento com o cliente, um fato que pode atrapalhar a produtividade e a qualidade do serviço.

Além disso, esse tipo de empresa conta com um trabalho considerado invisível, assim seus funcionários trabalham em constantes pressões pessoais, gerenciais, organizacionais e também provindas dos clientes. Portanto, o cotidiano de um Call Center constitui-se em um exemplo de trabalho contemporâneo, com diversos impactos.

Os funcionários de Calll Center recebem por mês em torno de um salário mínimo, mais as metas da empresa alcançadas por funcionários. Basicamente há dois tipos de colaboradores no Call Center: o receptivo e o prospectivo.

$\mathrm{O}$ receptivo fica na central de atendimento, recebe as chamadas dos clientes e as distribui para os atendentes. O prospectivo se refere aquele em que a empresa toma a iniciativa de contatar os clientes e consumidores atendidos. Assim, resulta em crescente adoecimento físico e mental.

A qualidade do serviço e a satisfação do cliente são conceitos interligados e observados pelos consumidores. Na perspectiva do consumidor a satisfação está ligada a uma busca 
individual ou um objetivo que será alcançado por meio do consumo de produtos ou serviços. No Entanto, as expectativas podem elevar ou diminuir a satisfação do cliente.

Não se deve esquecer que se o clima organizacional não for agradável, provavelmente os operadores não terão a devida motivação para realizarem um bom atendimento. O clima é favorável quando proporciona satisfação das necessidades pessoais e elevação da moral, e o mesmo é desfavorável quando proporciona frustração dessas necessidades.

\section{REFERENCIAL TEÓRICO}

É de extrema importância que a empresa Neobpo, especialista na terceirização de processos de negócios e serviços, dentro do Call Center, possua um gerenciamento que seja muito eficiente, pois normalmente os salários são baixos, precisando mais ainda incentivar a equipe para que ela esteja sempre motivada. O treinamento deve ser contínuo para que os operadores consigam atender os clientes de forma adequada, sanando todas as suas dúvidas. “À área de Recursos Humanos compete simplesmente descrever e analisar os cargos já estruturados para poder recrutar, selecionar, treinar, avaliar e remunerar seus ocupantes." (CHIAVENATO, 2005, p. 121).

Sabemos que a administração de pessoas é uma responsabilidade de linha e uma função de staff, ou seja, são dirigidas por estimular a importância de treinamento e desenvolvimento, reconhecendo que a empresa está preocupada com seu bem-estar, o que aumenta sua produtividade, tendo uma redução de custos com relação às doenças de trabalho, estreitando o relacionamento interpessoal dentro da empresa e facilitando processos. É uma peça chave para a empresa mostrar o conhecimento para os colaboradores. Dentro da empresa de Call Center geralmente quem assume a responsabilidade de linha é um supervisor junto com um coordenador de operações. Sua aplicação necessita de um acompanhamento adequado, seguindo os métodos utilizados pela gestão de pessoas, que serão executados por profissionais do departamento pessoal. (CHIAVENATO, 2005, p. 90).

Para Chiavenato (2005), o gerenciamento de pessoas requer sete aspectos fundamentais:

a) Escolha da equipe de trabalho: recrutamento e seleção dos participantes da equipe;

b) Desenho do trabalho da equipe: estruturação das tarefas e atribuições de cada membro;

c) Treinamento: contínuo treinamento e desenvolvimento dos participantes, enriquecendo o conhecimento, as habilidades e as competências;

d) Liderança: condução, orientação e impulsionamento dos membros da equipe;

e) Motivação: incentivo contínuo dos membros da equipe e administração de conflitos; 
f) Avaliação de desempenho da equipe: retroação e autodesenvolvimento pessoal de cada membro;

g) Remuneração da equipe: estabelecimento de um sistema de recompensas com base no desempenho e nos resultados alcançados;

\section{O Comportamento Humano nas Organizações}

Compreender o comportamento humano talvez seja o maior desafio que se tem para se conhecer bem as características das pessoas, pois dessa forma fica mais fácil compreender cada um dentro de sua organização. O grande problema talvez esteja em entender por que as pessoas são diferentes, agem de maneiras e formas tão distintas uma das outras. A primeira causa é a própria programação genética. Da forma que nascemos com uma programação genética para que tenhamos um funcionamento orgânico, também nascemos com uma programação genética para nossa estrutura emocional, refletindo nos padrões comportamentais, de habilidades e de aptidões. (CAMPELO, 2014).

A segunda causa, também cientificamente comprovada é a variável social, ou seja, o meio onde vivemos. (CAMPELO, 2014). É a variável social que nos diz de onde viemos, o que gostamos ou não, nossas referências, escolhas musicais ou políticas, entre outros. O homem tem sua capacidade limitada de acordo com o que pretende, não tendo capacidade para se comportar de todas as formas, pois suas características são limitadas e restritas.

Isso torna o comportamento humano variável, pois tanto sua capacidade física ou mental tem limitações. Temos diferentes necessidades e um fator tende a motivar o comportamento de uma pessoa hoje, porém no dia seguinte esse fator pode não ter força o suficiente para determinar seu comportamento, assim sendo influenciadas por várias necessidades apresentadas.

O comportamento é premeditado, proativo e cognitivamente ativo, tanto que pode ser analisado em termos e planos comportamentais que progride em estímulos para alcançar seus objetivos. De grande importância é a participação de pessoas nas organizações, pois as conduz ao envolvimento com os grupos, nos quais elas procuram manter sua identidade, segurança psicológica e utilizam o seu convívio com os outros membros para obter informações sobre si.

Os colaboradores também são vistos como recursos dentro das organizações, que carregam habilidades, poder de produção, responsabilidades, competências entre outras atribuições. O comportamento é orientado para a satisfação das suas necessidades pessoais e 
para alcançar objetivos. As pessoas podem resistir ou colaborar com as políticas e métodos das organizações dependendo das estratégias de liderança adotadas. (CHIAVENATO, 2009).

O comportamento humano está vinculado a vários fatores, desde a natureza humana até o sistema sensorial, personalidade, autoestima, caráter, sentimentos, até gerar a aprendizagem. Esses componentes moldam nosso comportamento, permitindo nos adaptar aos meios que atuamos. (SILVA, 2003).

Isso nos faz pensar nos comportamentos orientados para a satisfação das necessidades pessoais e objetivos, por isso reagimos e respondemos ao seu ambiente, tanto na organização como fora dela.

Os valores individuais variam entre si, mas costumam refletir os valores da sociedade na qual o indivíduo foi criado, sendo uma valiosa ajuda para a explicação e a previsão de comportamento. Robbins (2005) fala que as atitudes não são o mesmo que valores, mas ambos estão inter-relacionados. Dentro das organizações as atitudes são importantes, pois afetam o comportamento no trabalho. Por esse motivo as empresas estão investindo em treinamentos para remodelar as atitudes de seus funcionários.

\section{Conflitos nas Relações Organizacionais}

Compreendemos que em uma organização sempre haverá conflitos, ainda mais no setor de Call Center, pois há um número maior de pessoas e sempre haverá pensamentos e opiniões diferentes, e com isso os desentendimentos. Saber lidar com isso é o segredo.

No entanto, muitos conflitos são desnecessários e destroem valores, causando prejuízo para as empresas e pessoas que nela trabalham. O principal desafio dos gestores é identificar os produtivos e os contra produtivos, visando sempre gerenciá-los.

Há vários tipos de conflitos, sendo entre eles:

a) Conflito latente: este não é declarado e não há uma clara consciência de sua existência por parte dos envolvidos.

b) Conflito percebido: acontece quando as partes percebem e compreendem que o conflito existe ao sentirem que seus objetivos são diferentes dos objetivos dos outros e que existem oportunidades de interferência ou bloqueio.

c) Conflito sentido: atinge ambas as partes, emoções de diversos âmbitos e acontece de forma consciente onde existe o sentimento de raiva ou medo entre uma pessoa e outra e o mesmo não é manifestado. 
d) Conflito manifesto: pode ser chamado também de conflito aberto e trata-se daquele que já atingiu ambas as partes, já sendo percebido por terceiros e pode interferir na dinâmica da organização. (MARQUES, 2019).

Os conflitos no Call Center podem acontecer entre duas pessoas ou até mesmo entre grupos e abalam de maneira direta ou indireta o trabalho de determinado time ou colaborador. Diversos foram os conceitos definidos para conflito: Wisinski (1995), afirma que: "O conflito nos tempos atuais é inevitável e sempre evidente. Entretanto, compreendê-lo, e saber lidar com ele, é fundamental para o seu sucesso pessoal e profissional”. Existem ambientes e situações que potencializam a sua ocorrência, uma vez que não há esforço para que haja um bom entendimento e uma forma de trabalhar o assunto em debate sem que isso cause atritos maiores. Sempre existem motivos que causam os conflitos, sejam eles as mudanças no setor de trabalho, os recursos limitados, competição entre colaboradores, luta pelo poder, entre muitos outros fatores. Para comandar bem uma situação de conflito é essencial que as duas partes saibam se comunicar. A falta de diálogo traz impossibilidade, mas se a razão do conflito for boa e construtiva, um simples choque de opiniões pode trazer uma mudança importante e necessária.

Assim, é possível compreender que os conflitos são mais comuns do que pensamos. Só podemos saber identificar e resolver, ou tentar amenizar o máximo possível, para não ser prejudicial para o Call Center e a organização.

\section{Mudança organizacional e seus reflexos no comportamento humano}

Entende-se que as mudanças no Call Center se tornam cada vez mais inevitável, pois vem acontecendo com uma rapidez extraordinária, assim ficando difícil identificar como cada pessoa vai reagir a esses fatores, pois cada um tem sua personalidade própria.

Toda organização está sujeita a mudanças e em toda empresa existem aqueles que têm as melhores ideias, mas nem todos apreciam as mudanças. Os que fazem determinada empresa crescer são aqueles que atingem as metas o mais rápido possível, os que não veem problema em aceitar ideias, estão sempre dispostos a inovar, e estão sempre de acordo com as normas. (SPECTOR, 2008, p. 344-345).

Por gostarem de tomar decisões e fazer tudo que está ao seu alcance, muitos causam inveja, pois recebem grandes elogios e um crescimento profissional. O momento pode atestar complicado, mas muitas pessoas não se deixam abater, pois sempre reconhecem o melhor antes de qualquer pessoa. São considerados líderes proativos. 
Há também aqueles que apoiam os proativos, estão do lado para qualquer imprevisto. Não querem saber se a ideia é boa ou ruim, apenas apoiam o que os proativos falam e fazem. São muito fiéis, se arriscam apoiando, mas não fazem ideia disso. Gostam mesmo é de colaborar com tudo, sem má vontade. Assim como os proativos, quando as ideias são boas e lucrativas eles são reconhecidos pelo apoio dado à empresa.

Diferentes dos apoiadores incondicionais estão os apoiadores condicionais. Eles só apoiam quando têm certeza que não tem mais jeito e que a mudança fará bem à organização, pois se arriscam menos, mas quando apoiam é para valer. São mais inseguros, só acreditam quando veem acontecendo.

Conforme Sobral e Peci (2008, p. 207-208), há também aqueles que não sabem o que realmente querem, mudam de ideias rápido demais, tanto faz se eles estão determinados a colaborar. São submissos e vão muito pelas ideias dos outros. Têm medo de falar e de se impor para não serem mal vistos. Perdem o foco muito rápido, pois são vulneráveis e por incrível que pareça representam o maior número de pessoas de uma organização: são os indecisos.

E por último estão aqueles que não são a favor da mudança, aqueles que só veem o negativo, aqueles que não pensam na melhora da organização. Esses podem se manifestar contra qualquer decisão dada, são aqueles que só reclamam, os que mais faltam, menos trabalham, não dão nenhuma ideia motivadora para a organização e sempre falam mal de alguma coisa ou de alguém: esses são os reativos. Portanto, cada pessoa reage diferente com as mudanças, seja positivamente como negativamente, e estamos sujeitos a tudo isso desde sempre. (SILVA, 2019).

Para tentar fazer com que seus colaboradores se mantenham motivados a Neobpo estimula, oferecendo plano de carreira, realizando processo seletivo interno, dando oportunidades aos operadores de crescerem dentro da empresa.

\section{METODOLOGIA}

Os dados foram coletados através de entrevistas semiestruturadas, observações do ambiente organizacional, consulta ao site da empresa e a documentos institucionais. Foram realizadas entrevistas semiestruturadas que envolveram coordenadores, supervisores e operadores. Após coletados, os dados foram analisados qualitativamente, tendo por embasamento os aportes teóricos: 
a) Reconhecer as diferenças individuais, não tratando os colaboradores como se fossem todos iguais, pois eles possuem necessidades diferentes;

b) Definir objetivos e fornecer feedback. Deve-se trabalhar com objetivos que sejam específicos, desafiantes e que possam ser monitoráveis. Permitir que os colaboradores saibam como estão se saindo;

c) Estimular a participação nas decisões, permitindo ou encorajando a participação dos colaboradores nas decisões que os afetam, como a fixação de objetivos ou a definição dos procedimentos de trabalho.

No que tange à natureza da pesquisa, seguiu-se os seguintes parâmetros:

a) Quanto à forma: pesquisa e de campo;

b) Quanto à finalidade: aplicada;

c) Quanto ao método de análise: propositiva;

d) Quanto à abordagem: qualitativa.

A pesquisa de campo foi realizada com aplicação de um questionário, constante no apêndice A, na empresa Neobpo ${ }^{6}$.

\footnotetext{
${ }^{6}$ A Neobpo é uma empresa terceirizada no ramo de Call Center, com tecnologia moderna, buscando sempre inovar e capacitar os operadores através de treinamentos e cursos (NeoFuture). A Neo foi criada a partir da divisão dos negócios da Tivit, uma das maiores empresas brasileiras de serviço de tecnologia, para atender de forma especializada serviços de atendimento automatizado de clientes, conhecida como BPO. Com o portifólio completo e abrangendo os principais setores do mercado, oferecendo uma cultura de inovação, guiando os clientes para escolher a melhor estratégia de implementar as soluções de forma personalizada.
} 


\section{DESENVOLVIMENTO DA PESQUISA DE CAMPO}

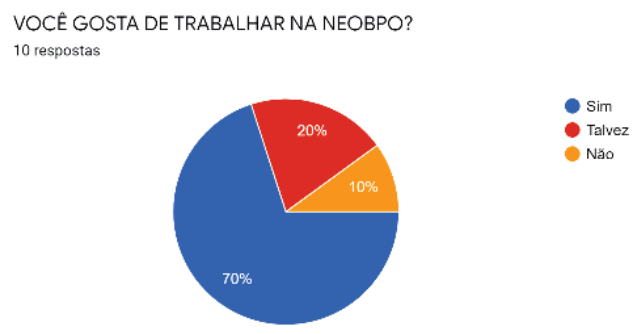

Nesta questão, $70 \%$ dos entrevistados afirmaram gostar de trabalhar na Neobpo. A empresa tem programas internos de reconhecimento, plano de carreira, e oferece aos funcionários benefícios como vale refeição, vale transporte e plano de saúde.

A SUA REMUNERAÇÃO É COMPATIVEL COM AS ATIVIDADES EXERCIDAS? 10 respostas

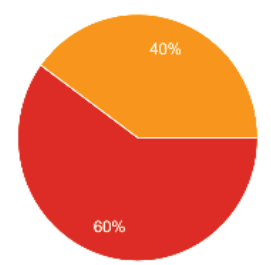

- SIM

Nāo

$60 \%$ dos entrevistados responderam que a sua remuneração está na média, levando em consideração as atividades realizadas na empresa, pois tem dias que as demandas de atividades são inesgotáveis.

VOCÊ SE SENTE DESMOTIVADO NA ATUAL EMPRESA? 10 respostas

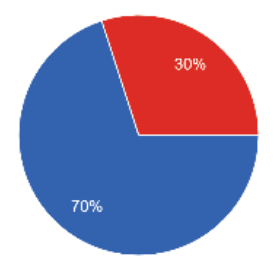

- Sim

Às vezes, cobranças excessivas e interesses pessoais não atendidos fazem com que $70 \%$ dos entrevistados fiquem desmotivados. Conforme Sobral e Peci (2008, p. 207-208), há também aqueles que não sabem o que realmente querem, mudam de ideia rápido demais, tanto faz se eles estão determinados a colaborar. 
A SUA EMPRESA INVESTE EM DIVERSIDADES?

10 respostas

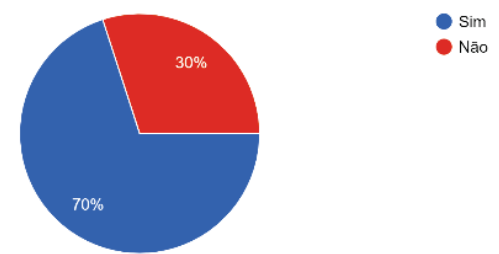

Nesta questão, 70\% dos entrevistados afirmaram que a empresa Neobpo investe em programas, palestras, comemorações de datas especiais relacionada à diversidade.

VOCÊ ACHA SEU GESTOR PREPARADO PARA SUPERVISIONAR A EQUIPE? 10 respostas
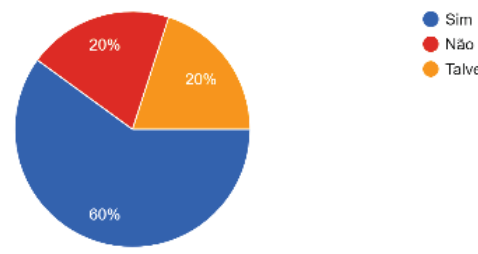

- Não

Aqui, $60 \%$ dos entrevistados afirmaram que seu gestor está apto para assumir os desafios e gerenciamento da equipe. A capacidade de ser exigente quando precisa obter um resultado; a seriedade com que encara as situações e desenvolve as atividades; a noção de justiça e o exemplo da disciplina; e a capacidade de ordenar o que precisa ser seguido, ser realizado. (Campelo 2014, pag. $80)$.

VOCÊ DIÁLOGA COM SEU SUPERIOR?

10 respostas

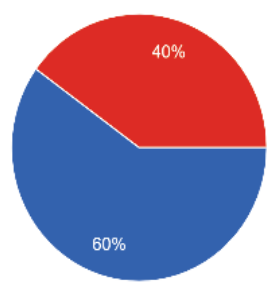

NÃO

Nesta questão $60 \%$ dos entrevistados afirmaram ter um bom diálogo com o seu superior, por ele ser um profissional sociável. O comportamento é orientado para a satisfação das suas necessidades pessoais e para alcançar objetivos. As pessoas podem resistir ou colaborar com as políticas e métodos das organizações dependendo das estratégias de liderança adotadas. (CHIAVENATO, 2009). 
SEU GESTOR LHE DÁ AUTONOMIA PARA TRABALHAR? 10 respostas

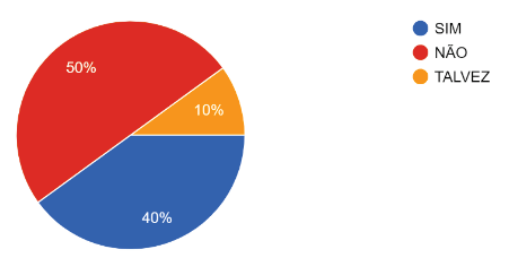

50\% dos entrevistados não recebem autonomia para tomar decisões imediatas, por conta da política e cultura da empresa que impede o colaborador de resolver certas situações em que às vezes necessita de flexibilidade.

VOCÊ SE ACHA COMPETENTE NO CARGO QUE EXERCE?

12 respostas

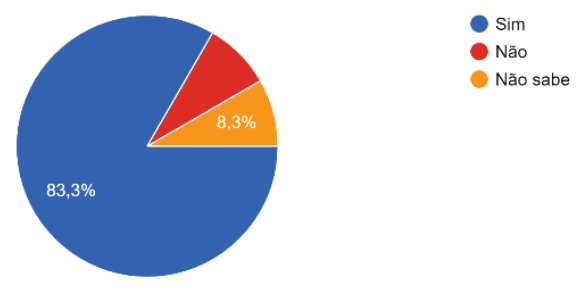

$83,3 \%$ dos entrevistados afirmam estarem exercendo suas atividades com competência. Sua aplicação necessita de um acompanhamento adequado, seguindo os métodos utilizados pela gestão de pessoas que serão executadas por profissionais do departamento pessoal. (CHIAVENATO, 2005, p. 90).

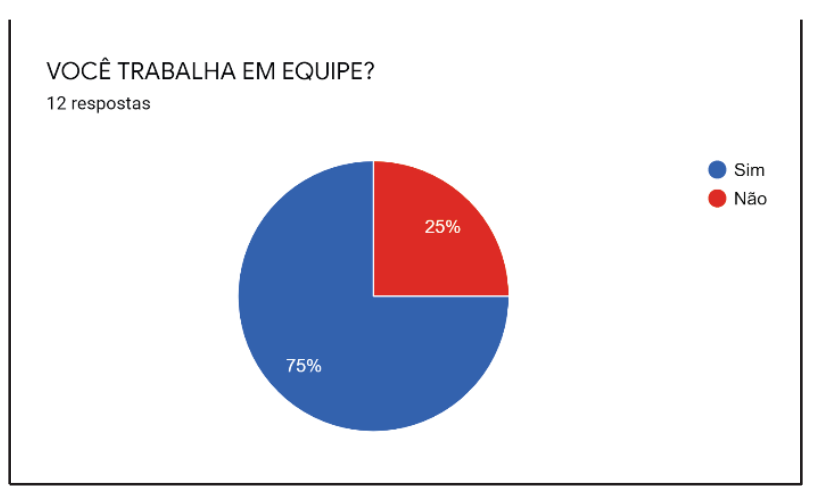

De acordo com o gráfico apresentado, $75 \%$ dos colaboradores responderam positivamente ao afirmarem que mantém um trabalho em equipe. 
VOCÊ É FELIZ EM TRABALHAR AQUI?

12 respostas

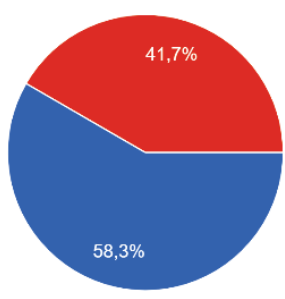

Sim

Não

$53 \%$ dos entrevistados afirmaram ser feliz em trabalhar na NEOBPO. Considera-se um número abaixo do esperado. Os que fazem determinada empresa crescer são aqueles que atingem as metas o mais rápido possível, os que não veem problema em aceitar ideias, estão sempre dispostos a inovar, e estão sempre de acordo com as normas. (SPECTOR, 2008, p. 344-345).

VOCÊ TEM DOMINIO NO SISTEMA AO QUE OPERA?

12 respostas
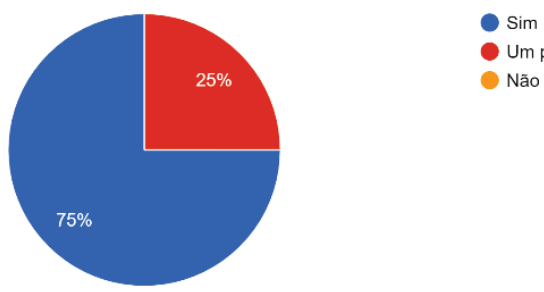

Um pouco

Não

$75 \%$ dos entrevistados têm domínio sobre o sistema no qual atuam, identificando que os sistemas têm as ferramentas necessárias para uso profissionais e afins. Robbins (2005) cita que as atitudes não são o mesmo que valores, mas ambos estão inter-relacionados. Dentro das organizações as atitudes são importantes, pois afetam o comportamento no trabalho. Por esse motivo as empresas estão investindo em treinamentos para remodelar as atitudes de seus funcionários. 
VOCÊ GOSTA DO SEU HORÁRIO DE TRABALHO?

12 respostas

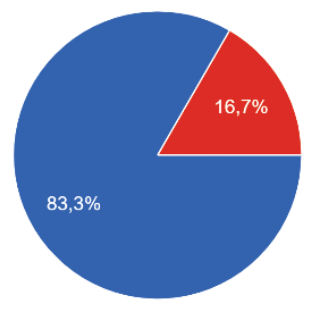

Năo

$83,3 \%$ dos entrevistados responderam estar satisfeitos com o seu horário de trabalho.

QUAL HORÁRIO VOCÊ GOSTARIA DE TRABALHAR?

12 respostas

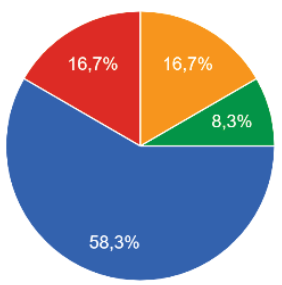

matuTino

INTERMÉDIO

TARDE

Nesta questão 58,3\% dos colaboradores responderam que gostariam de trabalhar na parte da manhã. Portanto, cada pessoa reage diferente com as mudanças, seja positivamente como negativamente, e estamos sujeitos a tudo isso desde sempre. (SILVA, 2019).

O SEU GESTORÉ ALEGRE?

12 respostas

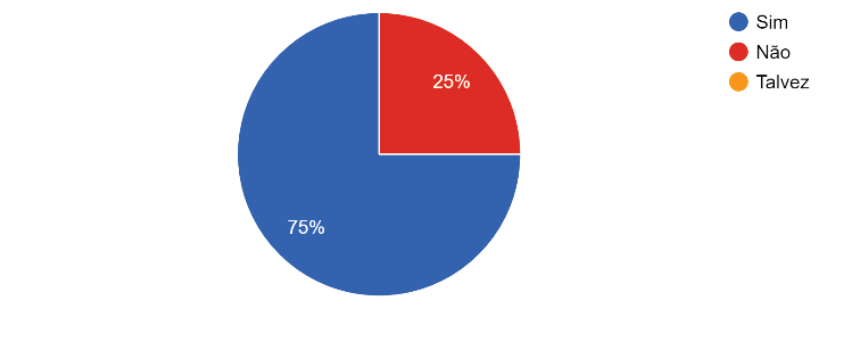

Sim

- Năo

Talvez

$75 \%$ dos entrevistados consideram o seu gestor uma pessoa alegre. Isso torna o clima organizacional mais harmonioso. 
O SEU GESTORÉ COMPREENSIVEL?

12 respostas

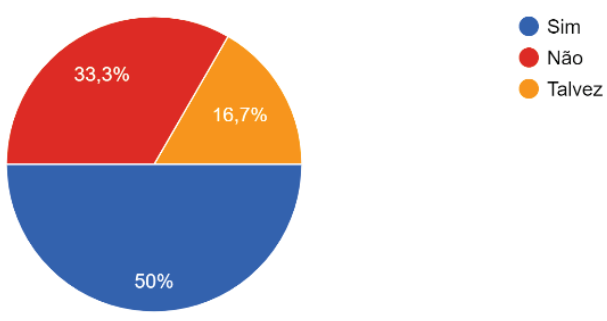

Nesta questão nota-se que $50 \%$ dos entrevistados afirmaram ter um gestor compreensível. Wisinski (1995) afirma que: “O conflito nos tempos atuais é inevitável e sempre evidente. Entretanto, compreendê-lo, e saber lidar com ele, é fundamental para o seu sucesso pessoal e profissional".

VOCÊ DIÁLOGA COM SEU SUPERIOR?

12 respostas

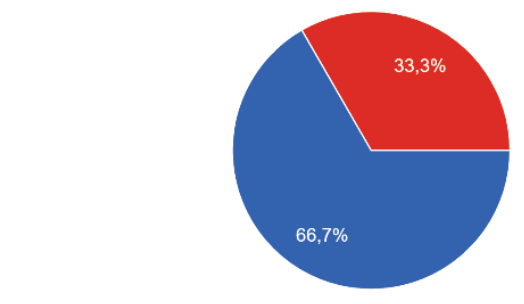

NÃO

A maioria dos entrevistados mantém um bom diálogo com o seu superior, a fim de manter uma boa relação entre líder e liderado.

\section{CONSIDERAÇÕES FINAIS}

Esse trabalho possibilitou conhecer de forma mais ampla a história da Neobpo e seus avanços em plena pandemia, assim como a vida dos operadores. Houve uma mudança muito produtiva para todos que trabalham na empresa para poder continuar suas atividades sem prejudicar os clientes. A empresa adotou o sistema home office para continuar o atendimento. Dessa forma, trouxe uma comodidade tanto para os trabalhadores e também para os clientes que não deixaram de receber seus atendimentos através do serviço prestado pela empresa. Mesmo com essas mudanças a empresa continuou dando lucro e continuou contratando pessoas para ocupar cargos importantes na empresa, porém, mesmo com tantas mudanças, a 
empresa usa a fragilidade do país, sobretudo no momento que estamos enfrentando, para causar medo nos operadores.

Ao verificar o medo de cada pessoa que faz parte dessa organização foi identificado que nem tudo que se fala é praticado no ambiente de trabalho, pois a situação piora a cada momento, e durante a pandemia houve muitas mudanças e a empresa está aproveitando do relaxamento da CLT e as brechas obtidas nas leis para assim informar que está com problemas financeiros. Todos percebem que não existe nenhuma dificuldade, pois a empresa demite um colaborador hoje e contrata outro no dia seguinte.

Diante do exposto é recomendável que todos busquem sempre se qualificar para garantir novas oportunidades.

\section{REFERÊNCIAS}

CAMPELO, Arandi Maciel. Gestão de pessoas: Compreendendo o comportamento humano nas organizações 6.ed. Recife: FcapBooks, 2014.

CHIAVENATO, Idalberto. Recursos humanos, o capital humano nas organizações. Disponível em: https://gennegociosegestao.com.br/resenha-recursos-humanos/

Acesso em: 12 abr. 2021.

CHIAVENATO, Idalberto. Comportamento Organizacional: a dinâmica do sucesso das organizações, Rio de Janeiro: Elsevier, 2005.

MARQUES, José Roberto. Conheça os tipos de conflitos nas organizações. São Paulo: 22 de novembro 2019. Disponível em: https://www.ibccoaching.com.br/portal/conheca-os-tiposde-conflitos-nas-organizacoes/ Acesso em: 12 maio 2021.

\section{NEOBPO. Quem somos.}

Disponível em: https://neobpo.com.br/quem-somos/

https://neobpo.com.br/transforme-a-experiencia-do-cliente-com-a-evolucao-tecnologica-doseu-website Acesso em: 12 maio 2021.

ROBBINS, Stephen P. Comportamento Organizacional: Tradução Reynaldo Marcondes. 11. ed. São Paulo: Pearson Prentice Hall, 2005.

SILVA, Francisco Souza. Liderança e comportamento organizacional: uma relação intrínseca na gestão. Edição v. 23 n. 37 (2019)

Disponível em: https://revista.pgsskroton.com/index.php/rcger/article/view/6493

Acesso em: 23 mar. 2021.

SILVA, Gustavo Melo. Implementação de mudança: uma aplicação de um sistema de medição de desempenho - SMD. 2003. 
Disponível em: https://www.estantevirtual.com.br/livros/filipe-sobral-e-alketapeci/administracao-teoria-e-pratica-no-contextobrasileiro/1875420975?gclid=Cj0KCQjw5PGFBhC2ARIsAIFIMNesJvDIMtwLCXPIDOI4c OS79Rt_DxBNRX31IzWXLK3EIx3T3RoLL-saAhmEEALw_wcB

Acesso em: 23 mar. 2021.

SOBRAL, Filipe; PECI, Alketa. Administração: teoria e prática no contexto brasileiro. São Paulo: Pearson Prentice Hall, 2008.

SPECTOR, Paul E. Psicologia nas organizações. Tradução Solange Aparecida Visconte. 2. ed. São Paulo: Saraiva, 2008.

WISINSKI, Jerry. Como resolver conflitos no trabalho. Tradução Renata Silva Cardoso. Rio de Janeiro: Campus, 1995.

\section{APÊNDICE A - Questionário utilizado na pesquisa de campo}

1. Você gosta de trabalhar na NEOBPO?
A. Sim
B. Talvez
C. Não

2. A sua remuneração é compatível com as atividades exercidas? *
A. $\operatorname{Sim}$
B. Na média
C. Não

3. Você se acha competente no cargo que exerce? *
A. $\operatorname{Sim}$
B. Não
C. Não sabe

4. Você se sente desmotivado na atual empresa? *
A. $\operatorname{Sim}$
B. Não

5. Você trabalha em equipe?*
A. $\operatorname{Sim}$
B. Não

6. Você é feliz em trabalhar aqui? *
A. $\operatorname{Sim}$
B. Não

7. Você tem domínio no sistema ao que opera? *
A. Sim
B. Um pouco
C. Não

8. Você gosta do seu horário de trabalho? *
A. $\operatorname{Sim}$
B. Não

9. Qual horário você gostaria de trabalhar? *
A. Matutino
B. Intermédio 
C. Tarde

D. Noite

\section{APÊNDICE B - Questionário para avaliação do gestor}

1. O seu gestor é alegre? *
A. $\operatorname{Sim}$
B. Não
C. Talvez
2. O seu gestor é compreensível? *
A. $\operatorname{Sim}$
B. Não
C. Talvez
3. Você dialoga com seu superior? *

A. Sim
B. Não 